\title{
“TUBEROUS SCLEROSIS COMPLEX”- WITH RARE MULTISYSTEM INVOLVEMENTS
}

\author{
Sunil Petkar1, Vivek Galani²
}

1Professor and HOD, Department of Dermatology \& VDL, Terna Medical College and Hospital, Navi Mumbai. ${ }^{2}$ Senior Resident, Department of Dermatology \& VDL, Terna Medical College and Hospital, Navi Mumbai.

\section{ABSTRACT}

\section{BACKGROUND}

Tuberous Sclerosis represents a genetic disorder of hamartoma formation in many organs, particularly the skin, brain, eye, kidney, and heart. It is now recognized that about half the families are linked to 9q34 (TSC1) and the other half to 16p13 (TSC2).

\section{KEYWORDS}

Tuberous Sclerosis, Rare Systemic Involvements, Topical Treatment with Sirolimus for Adenoma Sebaceum.

HOW TO CITE THIS ARTICLE: Petkar S, Galani V. "Tuberous sclerosis complex"- with rare multisystem involvements. J. Evolution Med. Dent. Sci. 2017;6(11):908-913, DOI: 10.14260/Jemds/2017/194

\section{CASE REPORT}

Patient 27 yrs., female, unmarried, not working, residing at Usmanabad, hailing from Maharashtra came with the chief complaint of-

1. Raised skin lesions all over the face and chest since age of 5 yrs.

2. Outgrowing lesions from both the great toe since age of 5 yrs.

3. Bleeding from nose since 3 months

4. Watery discharge from right ear since 3 months

5. U/L headache on right side since 8 days

6. Pain in jaw since 8 days.

- Pt. was apparently alright till the age of 5 years, then suddenly her mother noticed raised lesion on the nose which gradually spread to both side of face over the time. She also noticed similar lesion on the chest.

- Patient also complaint of outgrowing lesion from the great toe, which keeps growing and then sheds off by itself. Patient took treatment for the same lesion which was satisfactory and the lesion recurred later.

- On further inquiry, patient revealed that 9 months back she was admitted for the pain over both flanks, nausea, vomiting, headache with generalized weakness since 2 months, for which USG ABD. Was done, which was S/O multiple renal angiomyolipomas.

- Then 3 months back she developed bleeding from nose every 2-3 days watery discharge from ears and then she also developed $\mathrm{U} / \mathrm{L}$ right side headache and pain in jaws.

- No h/o seizures.

- No h/o mental retardation.

- No h/o trauma.

\section{Cutaneous Examination}

Multiple skin coloured to hyperpigmentation, dome shaped papules distributed B/L symmetrically over the nose, nasolabial fold, cheeks, chin forehead, eyelid measuring 1-5 $\mathrm{mm}$ in size. (Adenoma sebaceum, cutaneous angiofibroma) [Fig. 1, Fig. 2].

Financial or Other, Competing Interest: None.

Submission 28-12-2016, Peer Review 21-01-2017,

Acceptance 27-01-2017, Published 06-02-2017.

Corresponding Author:

Dr. Sunil Petkar,

\#1902, Zenith Chs,

Plot 3D, Sector- $46 A$

Nerul, Navi Mumbai-400706.

E-mail:drpetkar@hotmail.com

DOI: $10.14260 /$ jemds $/ 2017 / 194$
Single, well defined, skin coloured, raised and soft patches with irregular thickening and multiple dimples at the follicular openings, measuring $3 \times 3 \mathrm{~cm}$ in size present over back. (Shagreen's patch) [Fig. 3].

On Oral examinations, multiple well defined, hyperpigmented macules present over $\mathrm{B} / \mathrm{L}$ buccal mucosa and on tip of the tongue with multiple dental enamel pits and multiple interdental gingival fibromas. [Fig. 4, Fig. 5, Fig. 6, Fig. 7].

On nail examination, multiple, sooth, skin coloured, firm projections with hyperkeratotic tips arising from beneath the proximal and lateral nail folds and extending over the nail plate, measuring around $1 \mathrm{~cm}$ in size, from the both great toe. (Koenen's tumor) [Fig. 8]. Subungual hyperkeratosis present on both thumbs.

Contrast Enhanced CT Abdomen and Pelvis Reveals,

- Multiple renal angiomyolipomas bilaterally. [Fig. 14]

- Lymphangiomyomatosis in the visualized lung bases. [Fig. 17]

- Patchy sclerosis at most places in visualized axial skeleton. [Fig. 15 \& 16]

- Mild hepatomegaly with incidental right ovarian cyst and pelvic congestion. [Fig. 18]

\section{CT PNS reveals,}

- Changes of right maxillary sinusitis with relatively hyperdense contrast suggest possibility of,? Desiccated secretions,? areas of haemorrhage, ? secondary infections. [Fig. 11].

- Subependymal calcified tubers with possible subependymal giant cell ependymoma in the region of foramen of Monro. [Fig. 10].

\section{Plain MRI Brain Reveals,}

- Areas of subependymal calcification or tubers seen involving frontal horns, right occipital horn largest of size $9 \times 8 \mathrm{~mm}$. [Fig. 13]

- Patchy area of altered signal intensity of size $11 \times 11 \mathrm{~mm}$ on left side involving base of tongue. [Fig. 12]

- 2D echo/Doppler study- Normal

- Normal LVEF

- No pulmonary artery hypertension

- $\quad$ ECG- Normal

- EEG- normal, no epileptiform activity.

- Chest X-ray: NAD 


\section{Biopsy}

Biopsy of shagreen patch showed increased collagen in dermis with H\&E stain and Verhoeff-Van Gieson stain demonstrates increased red collagen and sparse black elastic fibers.

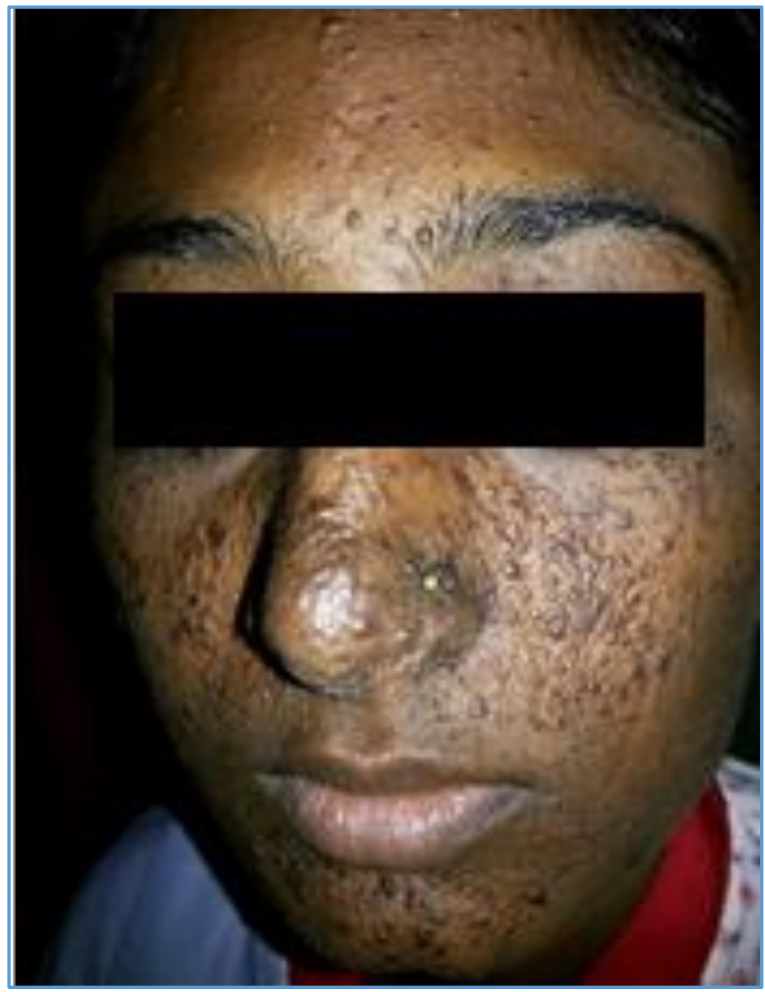

Figure 1

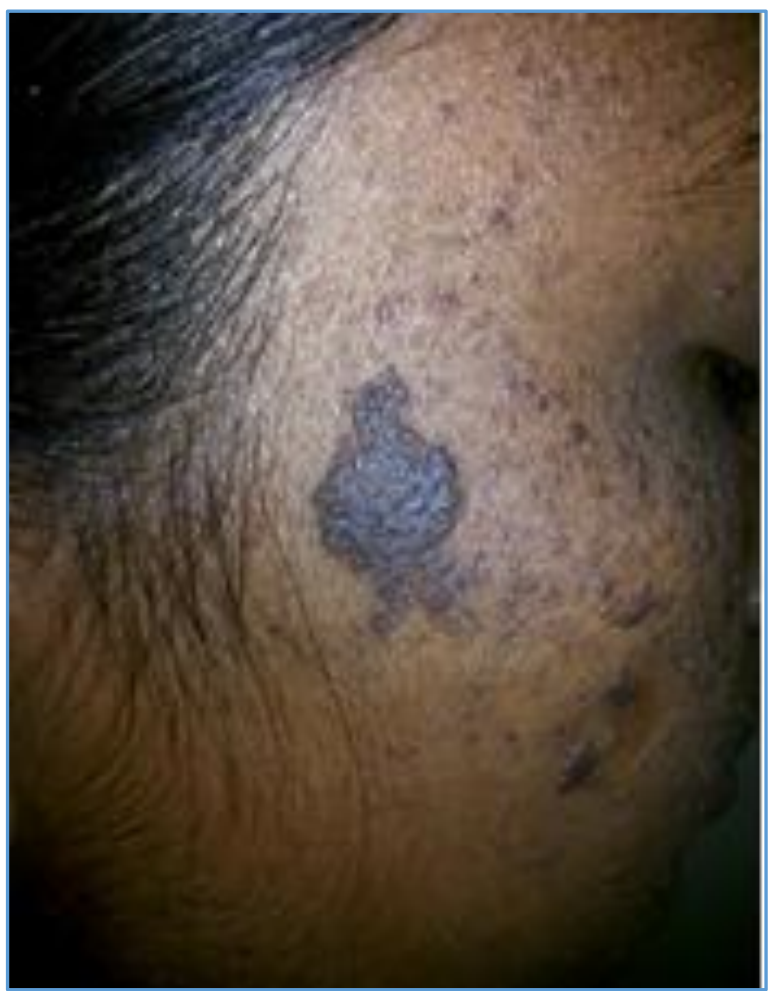

Figure 2

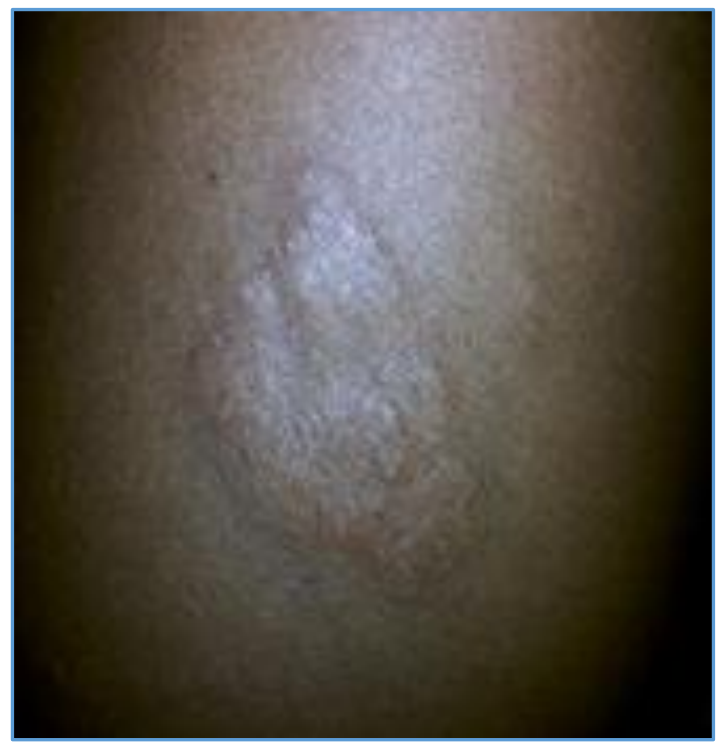

Figure 3

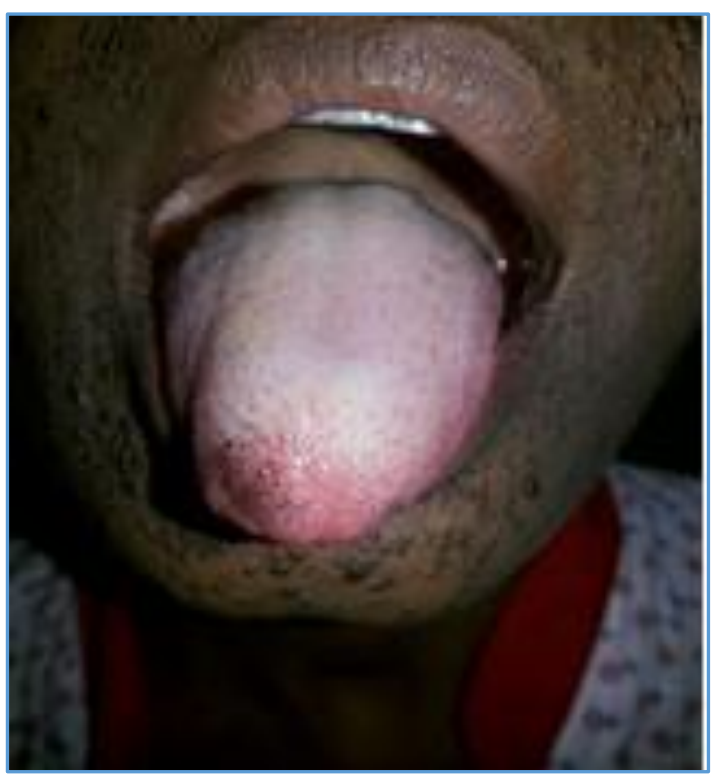

Figure 4

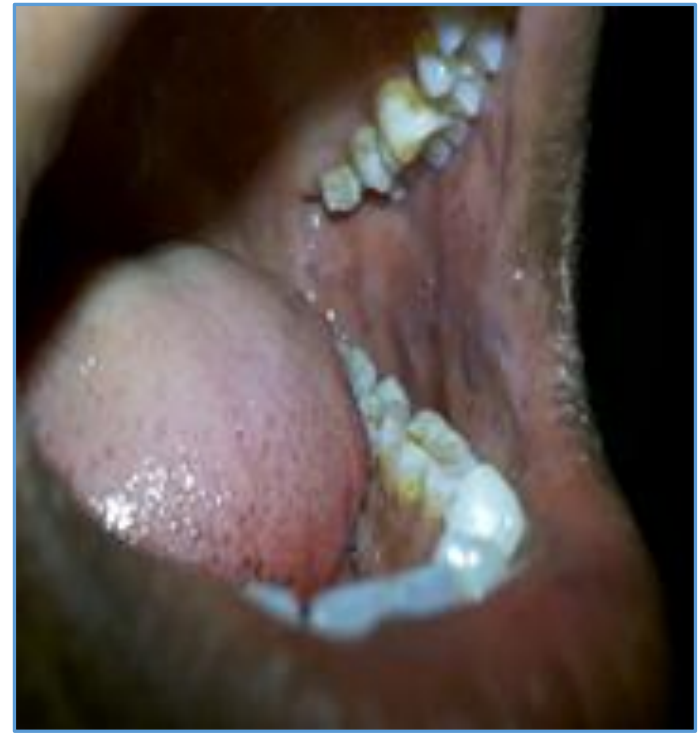

Figure 5 


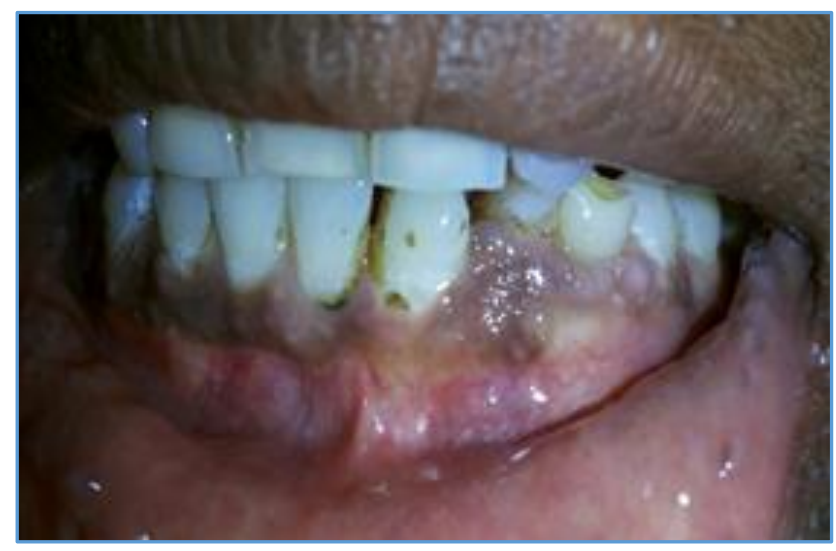

Figure 6

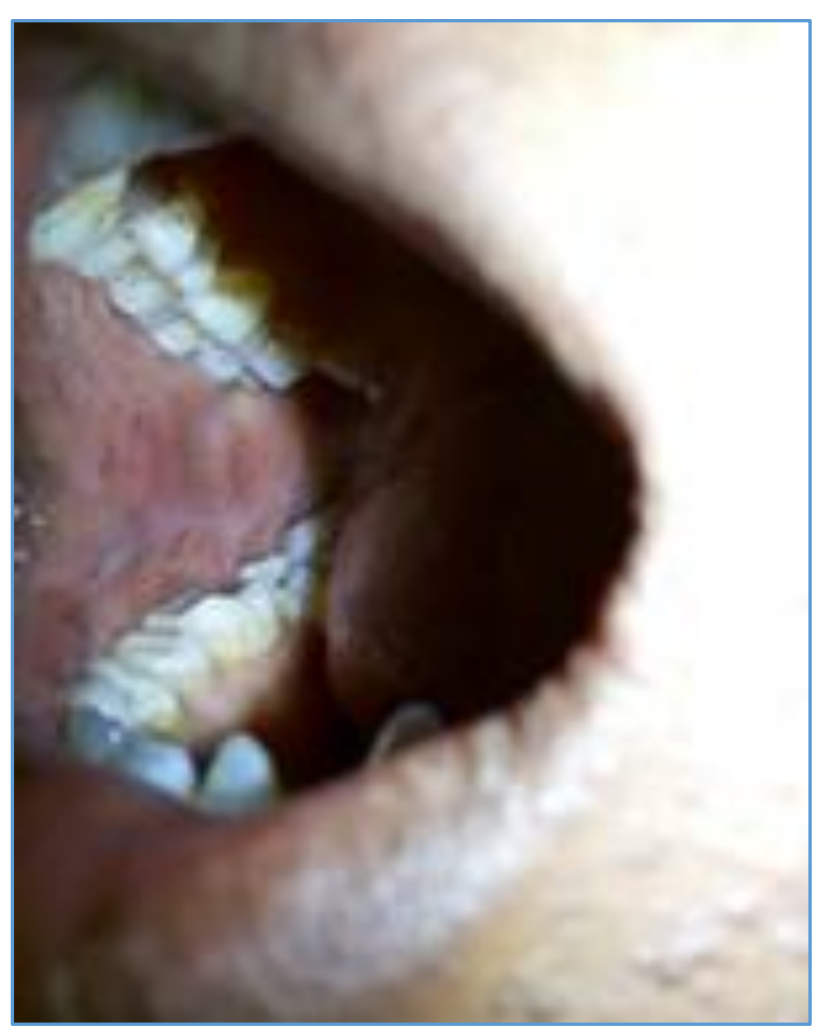

Figure 7

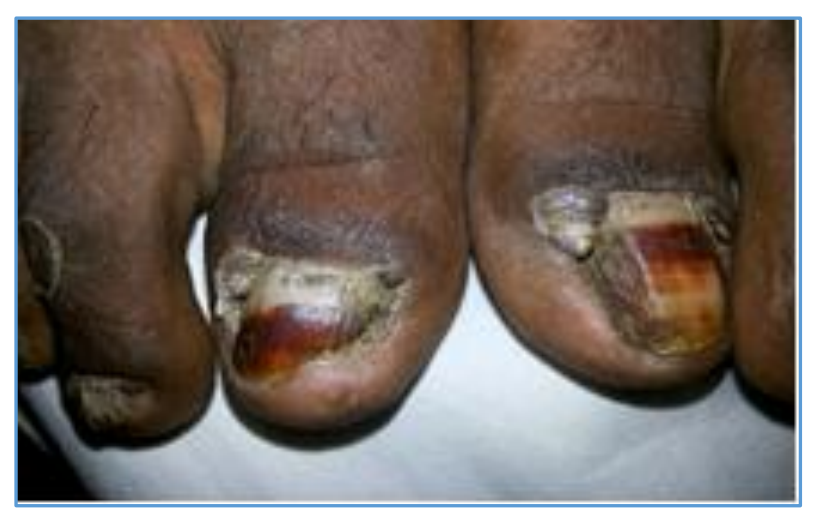

Figure 8

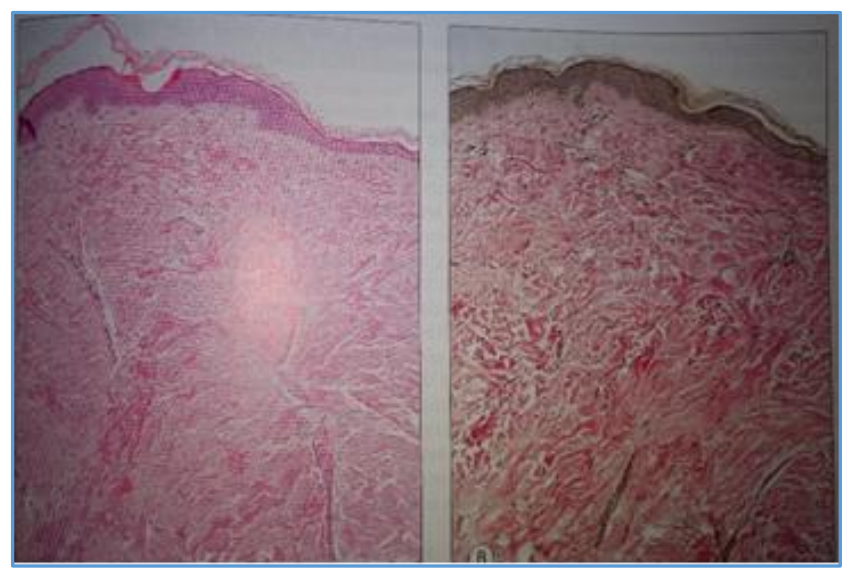

Figure 9

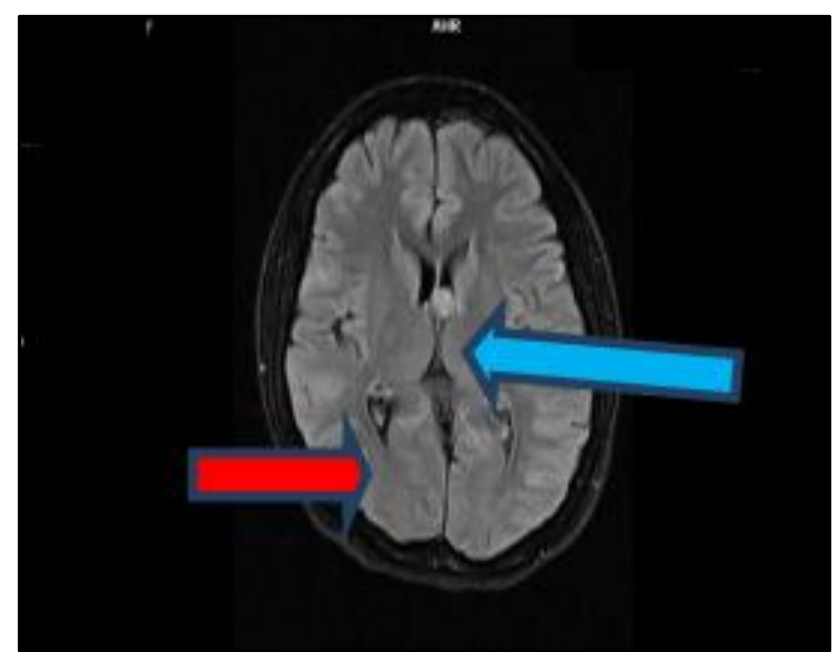

Figure 10

Nodular lesion in the region of foramen of Monro on the left suggestive of Subependymal giant cell astrocytoma.

Areas of subependymal calcification in relation to the right occipital horn.

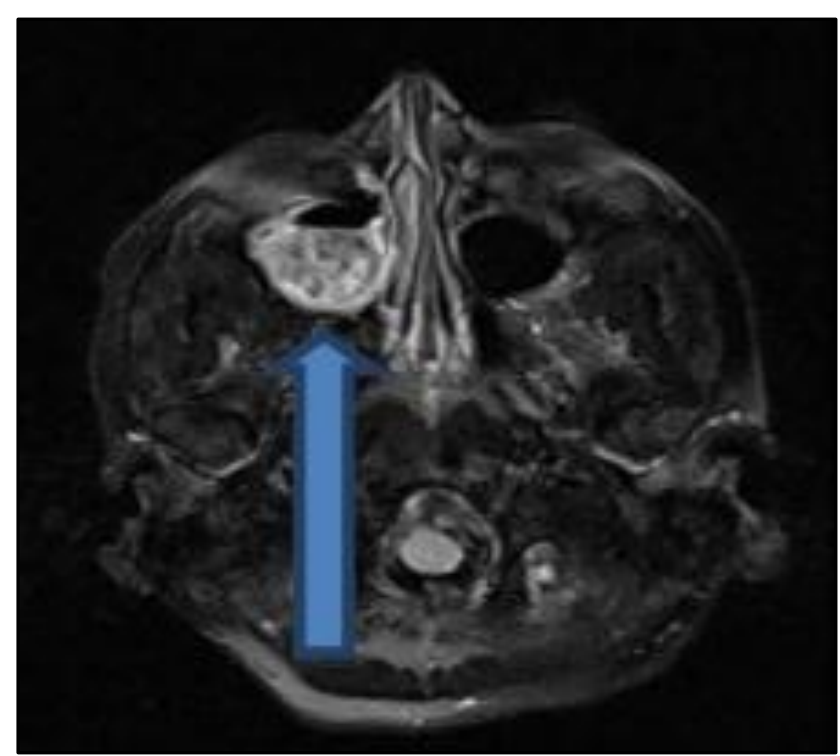

Figure 11. Maxillary sinusitis 


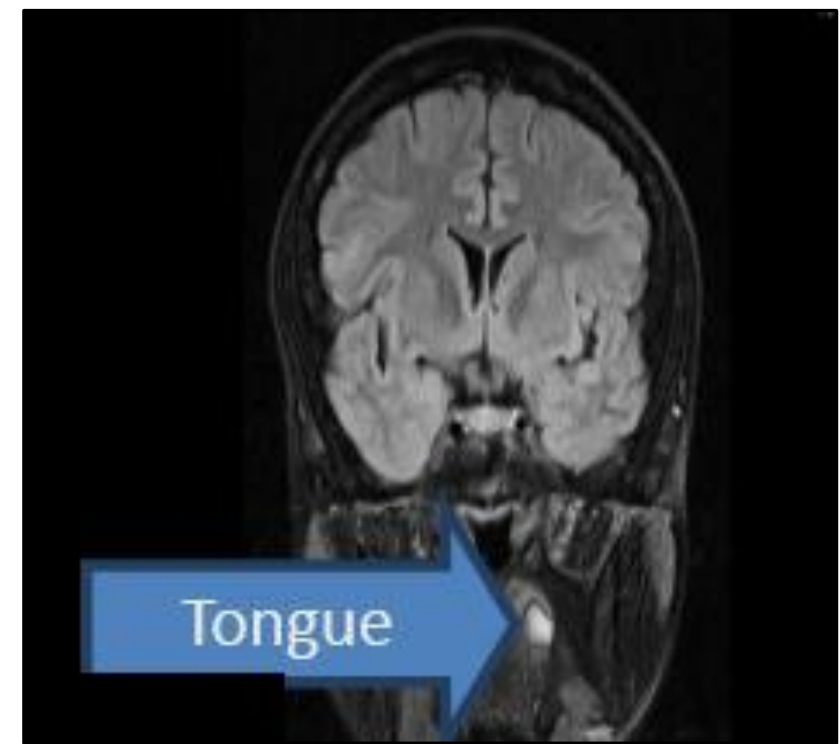

Figure 12. Patchy area of altered signal intensity of size 11 $X 11 \mathrm{~mm}$ on left side involving base of tongue

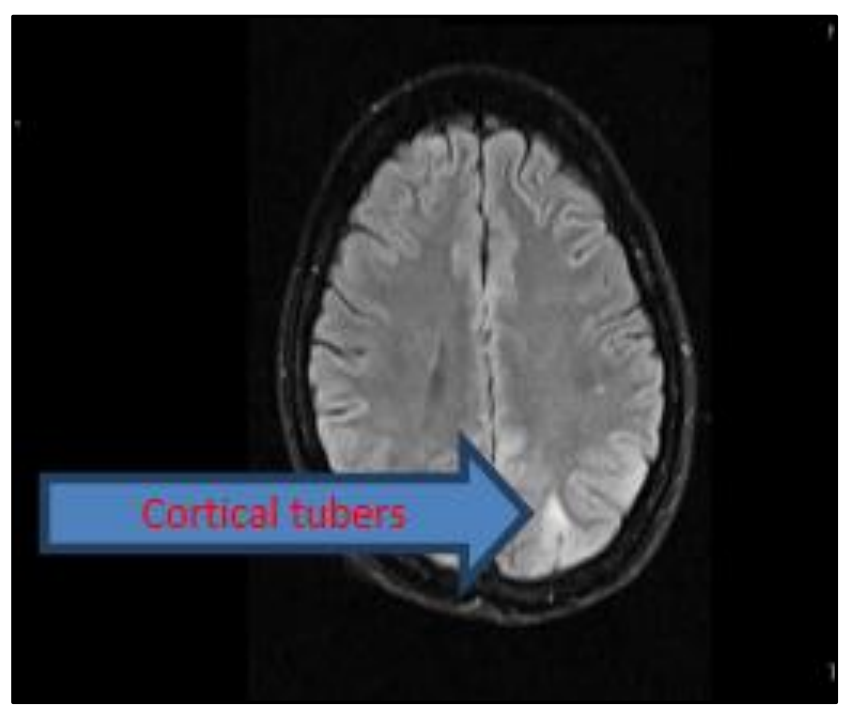

Figure 13

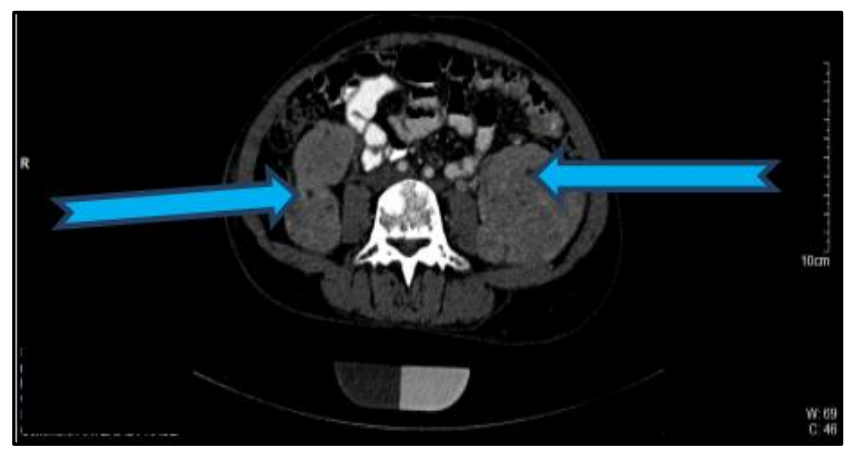

Figure 14

Bilateral enhancing mass lesions with fat attenuation areas within at most places in an intra-renal, perinephric and subcapsular locations suggestive of angiomyolipomas.

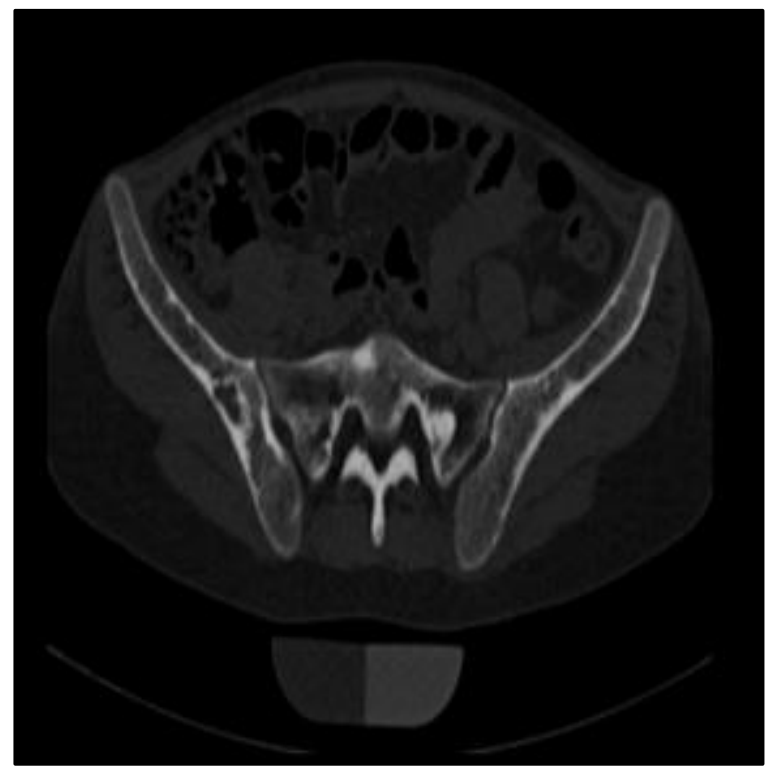

Figure 15

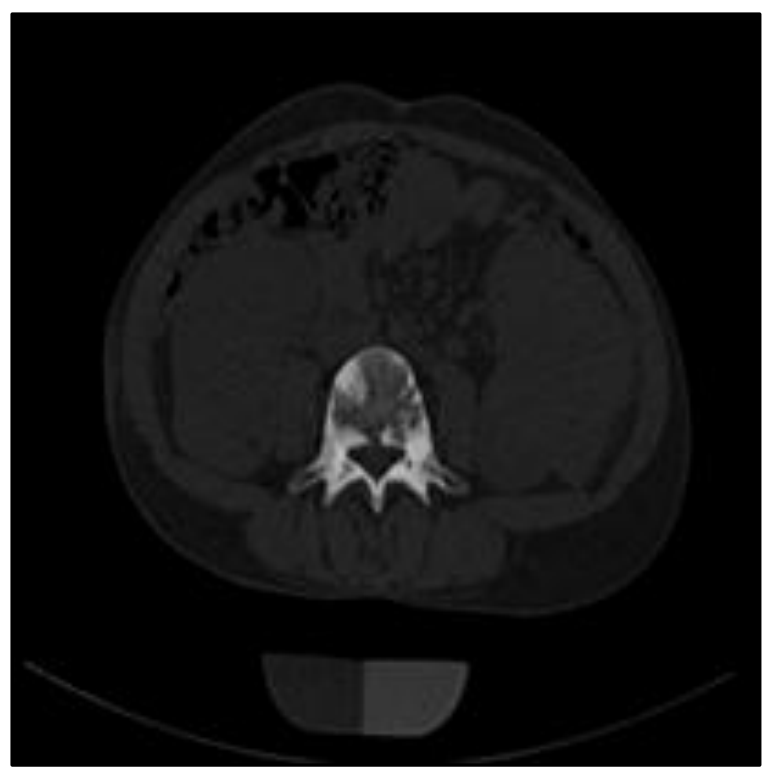

Figure 16. Patchy sclerosis was noted at most places in visualized axial skeleton on bone windows

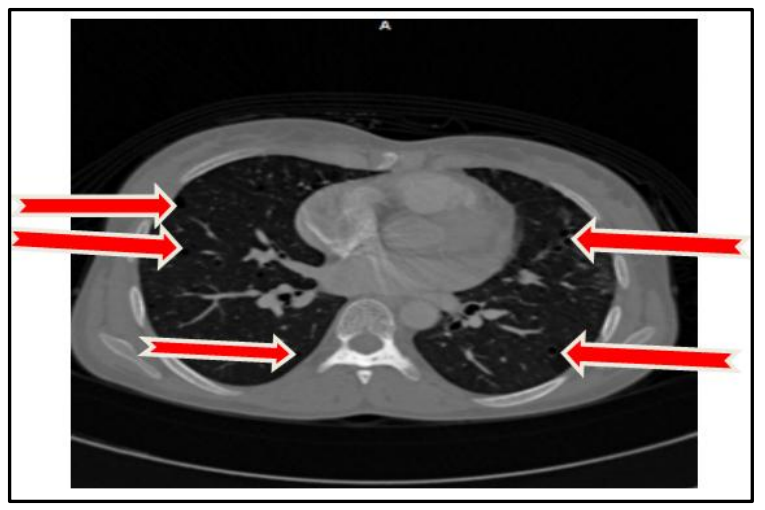

Figure 17. Lung bases covered in the CT ABD study showed multiple small well defined thin walled cystic lesions in both lungs suggestive of lymphangioleiomyomatosis 


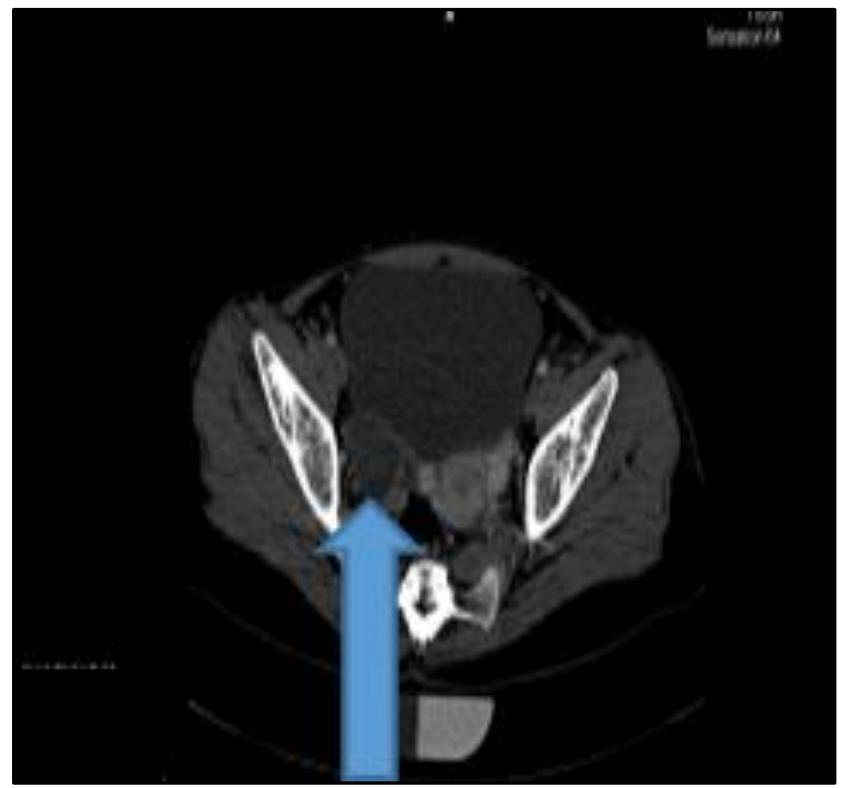

Figure 18. Incidental right simple adnexal/ovarian cyst with pelvic congestion

\section{DISCUSSION}

Tuberous sclerosis complex is an autosomal dominant neurocutaneous disorder in which multisystem hamartomas are seen. It is caused by the mutations in two genes: Tuberous sclerosis complex 1 on $9 \mathrm{q} 34.3$ that encodes the protein hamartin, and tuberous sclerosis complex 2 on 16 p13.3 that encodes the protein tuberin.[1] Normally, these suppressor proteins inhibit the activation of mammalian target of rapamycin (mTOR). Any mutation in these genes lead to the dysregulation of this inhibitory process, leading to uncontrolled cell growth, proliferation and protein synthesis that results in multi-organ hamartomas. [2] This disorder has an incidence of $1 / 6000$ births, and mostly affects the skin, kidneys, heart, brain and lungs.[1,3]

The cutaneous manifestations of tuberous sclerosis complex include angiofibromas, forehead fibrous plaques, hypomelanotic macules or confetti-like lesions, periungual fibromas and shagreen patches.[4] Facial angiofibromas are small, symmetrical, pink to red papules which coalesce to form plaques. They are composed of blood vessels and fibrous tissue, and are seen in approximately $80 \%$ of patients, making it the most frequent cutaneous finding of this disease.[5] According to the recommendations of the "International Tuberous Sclerosis Complex Consensus Conference 2012," they are considered as one of the major diagnostic criteria.[6] Although benign in nature, they can bleed or obstruct the nasal openings. [7] They cause great psychosocial burden to patients.[8] Therapeutic options included cryotherapy, electrocoagulation, dermabrasion, laser surgery and podophyllotoxin application. ${ }^{[9]}$

Epilepsy[10] is seen in almost all mentally retarded patients and in $70 \%$ of those with average intelligence. It usually begins in infancy or early childhood, thus often preceding the skin lesions by many years.

Ocular signs[11,12] occur in $50 \%$ of cases but may be hard to detect. Retinal phacomas are seen as white streaks along the vessels or as small, rounded tumours near the disc.

Cardiac and renal tumours are often asymptomatic unless by reason of their size or site.
Cardiac rhabdomyomas, detected by echocardiography, occur in over $50 \%$ of infants. ${ }^{[13,14]}$ Renal involvement includes angiomyolipomas , a benign tumour of the renal parenchyma, renal cyst.

Pulmonary changes are rare and seldom cause symptoms, but if extensive can result in increasing dyspnoea and recurrent spontaneous pneumothorax.

\section{Major Criteria}

1. Facial angiofibroma / forehead plaque.

2. Non-traumatic ungual / periungual fibroma.

3. Shagreen patches

4. Cortical tuber (Brain).

5. Subependymal nodules (Brain).

6. Subependymal giant cell astrocytoma (Brain).

7. Lymphangioleiomyomatosis (lung).

8. Renal angiomyolipoma.

9. Cardiac rhabdomyoma.

10. $>3$ hypomelanotic macules.

11. Multiple retinal nodular hamartoma.

\section{Minor Criteria}

1. Multiple random pits in enamel.

2. Non-renal hamartomas.

3. Gingival fibromas.

4. Hamartomatous rectal polyp.

5. Bone cysts.

6. Cerebral white matter radial migration lines.

7. Retinal achromic patch.

8. Confetti skin lesions.

9. Multiple renal cysts.

We also studied another 11 patients to evaluate the effectiveness and tolerability of topical sirolimus for facial angiofibromas in patients with tuberous sclerosis complex.

We investigated the effect and safety of topical $0.1 \%$ sirolimus, which was obtained by crushing sirolimus tablets and mixing it with petrolatum. The patients were asked to apply the cream to one side of their face, and Vaseline to the other side. The effect of topical sirolimus was evaluated using the "facial angiofibroma severity index."

There was a significant improvement in the redness and extension of the tumours on the sides to which the active ingredient was applied. Some side effects such as itching and irritation occurred in three patients, which were treated with topical hydrocortisone cream.

Topical sirolimus appears to be a promising, fairly well tolerated treatment, for facial angiofibromas, in patients with tuberous sclerosis complex. Although its efficacy diminishes with time, repetitive usage is effective.

\section{REFERENCES}

[1] Chopra M, Lawson JA, Wilson M, et al. An Australian tuberous sclerosis cohort: are surveillance guidelines being met? J Paediatr Child Health 2011;47(10):711-6.

[2] Wheless JW, Almoazen H. A novel topical rapamycin cream for the treatment of facial angiofibromas in tuberous sclerosis complex. J Child Neurol 2013;28(7):933-6. 
[3] Ng KH, Ng SM, Parker A. Annual review of children with tuberous sclerosis. Arch Dis Child Educ Pract Ed 2015;100(3):114-21.

[4] Tonekaboni SH, Tonekaboni SH, Tousi P, et al. Clinical and para clinical manifestations of tuberous sclerosis: a cross sectional study on 81 pediatric patients. Iran J Child Neurol 2012;6(3):25-31.

[5] Salido R, Garnacho-Saucedo G, Cuevas-Asencio I, et al. Sustained clinical effectiveness and favorable safety profile of topical sirolimus for tuberous sclerosisassociated facial angiofibroma. J Eur Acad Dermatol Venereol 2012;26(10):1315-8.

[6] Krueger DA, Northrup H. International Tuberous Sclerosis Complex Consensus Group. Tuberous sclerosis complex surveillance and management: recommendations of the 2012 international tuberous sclerosis complex consensus conference. Pediatr Neurol 2013;49(4):255-65.

[7] Foster RS, Bint LJ, Halbert AR. Topical 0.1\% rapamycin for angiofibromas in paediatric patients with tuberous sclerosis: a pilot study of four patients. Australas J Dermatol 2012;53(1):52-6.
[8] Bissler JJ, McCormack FX, Young LR, et al. Sirolimus for angiomyolipoma in tuberous sclerosis complex or lymphangioleiomyomatosis. $\mathrm{N}$ Engl J Med 2008;358(2):140-51.

[9] Schwartz RA, Fernández G, Kotulska K, et al. Tuberous sclerosis complex: advances in diagnosis, genetics, and management. J Am Acad Dermatol 2007;57(2):189-202.

[10] Curatolo P, Verdecchia M, Bombardieri R. Tuberous sclerosis complex: a review of neurological aspects. Eur J Paediatr Neurol 2002;6(1):15-23.

[11] Grover WD, Harley RD. Early recognition of tuberous sclerosis by fundoscopic examination. J Pediatr 1969;75(6):991-5.

[12] Rowley SA, O'Callaghan FJ, Osborne JP. Ophthalmic manifestations of tuberous sclerosis: a population based study. Br J Ophthalmol 2001;85:420-3.

[13] Bass JL, Breningstal GN, Swaiman KF. Echocardiographic incidence of cardiac rhabdomyoma in tuberous sclerosis. Am J Cardiol 1985;55(11):137982.

[14] Smith HC, Watson GH, Patel RG, et al. Cardiac rhabdomyomata in tuberous sclerosis: their course and diagnostic value. Arch Dis Child 1989;64(2):196-200. 